\title{
Optimalisasi Pelayanan Publik Bagi Pemimpin di Era Digitalisasi di Provinsi Riau
}

\author{
Ayub Khan \\ Badan Pengembangan Sumber Daya Manusia Provinsi Riau \\ email : tuanayub@gmail.com
}

\begin{abstract}
Abstrak
Permasalahan terhadap gamang teknologi di era kekinian sangatlah tidak wajar, karena aparatur sipil negara di harapkan harus mampu memanfaatkan penggunaan teknologi berbasis informasi yang sangat bermanfaat untuk tata kelola organisasi di pemerintahan. Usaha-usaha untuk mampu memanfaatkan teknologi baik berbasis website ataupun aplikasi yang telahdi design sedmikian rupa melalui situs resmi yang sumber datanya dapat di ketahui oleh publik agar mudah diakses dan dapat disebar luaskan agar publik dapat mengetahui dan memanfaatkan informasi yang ada dalam website dimaksud sebagai sumber informasi dari suatu sistem pemerintahan yang mungkin sangat bermanfaatuntuk di adopsi ataupun di adaptasi sebagai referensi suatu kebijakan yang telah di anolir untuk kepentingan yang lebih konrehensif. Dalam usianya yang ke 63 tahun, 9 Agustus 2020 ini, tata kelola pemerintahan di Provinsi Riau sesuai Undang-Undang Nomor 23 Tahun 2014 tentang Pemerintahan di Daerah, Riau terus berbenah dan seiring dengan kemajiuan teknologi digital di era 4.0 , untuk memberikan Pelayanan seoptimal mungkin kepada pengguna pelayanan publik, sebagaimana yang di amanatkan dalam Undang-Undang Nomor 25 Tahun 2009 dan Peraturan Pemerintah Nomor 96 Tahun 2009.Melalui situs resmi website Pemerintah Provinsi Riau telah melakukan upaya-upaya Pelayanan yang terintegrasi dimaksud dan dismaping di perlukan Grand Design Organisas digital di Provinsi Riau yang merupakan suatu inovasi daerah dalam terus meningkatkan kemajuan pembangunan dan kesehateraan masyarakat di daerah ini. Berkenaan hal tersebut, organisasi sebagaimana di ketahui merupakan sebuah wadah atau tempat berkumpulnya sekelompok orang untuk bekerjasama secara rasional dan sistematis, terkendali, dan terpimpin untuk mencapai suatu tujuan tertentu dengan memanfaatkan sumber daya yang ada. Pada umumnya organisasi akan memanfaatkan berbagai sumber daya tertentu dalam rangka untuk mencapai tujuan, seperti; uang, mesin, metode/ cara, lingkungan, sumber daya manusia, dan sumber daya lainnya, yang dilakukan secara sistematis, rasional, dan terkendali. Disamping hal tersebut .berdasarkan teori komunikasi hyper personal dan etika komunikasi di era digital ini. Peran pemimpin tetap diperlukan sebagai figur panutan dalam berperilaku, sehingga seorang pemimpin bagaimanapun tetap harus menjadi orang yang berkarakter terlebih dahulu sebelum berteriak mengenai karakter itu sendiri, agar proses interaksi melalui komunikasi yang sifatnya hyper personal akan mewujudkan kondisi masyarakat yang kita harapkan bersama.
\end{abstract}

Kata kunci ; Pemanfaatan Teknologi Informasi, digitalisasi, organisasi dan kepemimpinan

\begin{abstract}
The problem with technological giddiness in the present era is very unnatural, because the state apparatus is expected to be able to utilize information-based technology which is very useful for organizational governance in government. Efforts to be able to take advantage of technology either based on websites or applications that have been designed in such a way through the form of an official website whose data sources can be known by the public so that they are easily accessible and can be disseminated so that the public can see and take advantage of the information on the website used as a source of information from a government system that may be very useful to be adopted or adapted as a reference for policy policies that have been anolated for more comprehensive purposes.At the age of 63 years, 9 August 2020, governance in Riau Province in accordance with Law Number 23 of 2014 concerning Regional Government, Riau continues to improve and along with the advancement of technology in the digital era 4.0, to provide optimal services to Users of public services, the security mandated in Law Number 25 of 2009 and Government Regulation Number 96 of 2009. Through the official website of the Riau Provincial Government, efforts have been made to integrated and dismap services for the needs of the Grand Design of digital Organizations in Riau Province which is a regional innovation in enhancing the development of development and
\end{abstract}


community health in this area. In this regard, an organization that knows it is a container or a gathering place for a group of people who work rationally and systematically, in control, and are guided to achieve a certain goal by utilizing existing resources. In general, organizations will utilize certain resources in order to achieve their goals, such as; Money, machines, methods / methods, environment, human resources, and other resources, which are carried out in a systematic, rational and controlled manner.Besides this. based on hyperpersonal communication theory and communication ethics in this digital era. The role of a leader is still needed as a role model in behavior, so that a leader must be a person with character first before shouting about the character itself, so that the process of interaction through hyperpersonal communication will create the conditions of society that we see together.

Keywords; Utilization Teknologi Information, digitization, organization and leadership

\section{PENDAHULUAN}

Revolusi industri pertama terjadi pada abad 18, ketika ditemukan mesin- mesin bertenaga uap, yang membuat manusia beralih dari mengandalkan tenaga hewan ke mesin-mesin produksi mekanis. Revolusi industri kedua berlangsung di sekitar 1870 ketika industri dunia beralih ke tenaga listrik, ( james watt) yang mampu menciptakan produksi massal. Revolusi industri ketiga terjadi di era 1960-an saat perangkat elektronik mampu menghadirkan otomatisasi produksi. Dasawarsa industri dan manufaktur global bersiap menghadapi revolusi industri 4.0; dan 5.0.

Secara umum, definisi revolusi industri adalah ketika kemajuan teknologi yang besar disertai dengan perubahan sosial ekonomi dan budaya yang signifikan. Terminologi Revolusi Industri 4.0 pertama kali dikenal di Jerman pada 2011. Pada Industri 4.0 ditandai dengan integrasi yang kuat terjadi antara dunia digital dengan produksi industri. Revolusi industri 4.0 merupakan era digital ketika semua mesin terintegrasi melalui sistem internet atau cyber system. Suatu inovasi membawa perubahan yang signifikan pada publik.

Generasi yang lahir di tahun 1960-70-80an, adalah generasi yang mengalami loncatan teknologi yang begitu mengejutkan di abad ini, sebagian personal pernah mengalami pemanfaatan manual lampu petromax dan lampu minyak, sekaligus menikmati lampu bohlam, lampu TL, hingga LED. Generasi yang pernah menikmati riuhnya suara mesin ketik, sekaligus saat ini jari kita masih lincah menikmati keyboard dari laptop. Inilah generasi melinial yang mamu merekam lagu dari radio dengan tape recorder, sekaligus juga menikmati mudahnya men-download lagu dari gadget.

Revolusi Industri Jilid Empat memiliki potensi untuk meningkatkan tingkat pendapatan global dan meningkatkan kualitas hidup bagi masyarakat dunia, akan menghasilkan harga murah dan kompetitif, meningkatkan efisiensi dan produktivitas, menurunkan biaya transportasi dan komunikasi, meningkatkan efektivitas logistik dan rantai pasokan global, biaya perdagangan akan berkurang, akan membuka pasar baru dan mendorong pertumbuhan ekonomi. Era Digital merupakan terminologi bagi masa yang segala sesuatunya dihidupkan dengan teknologi. Mulai dari televisi, pendingin ruangan, lemari pendingin, komputer, telepon pintar, hingga pada penggunaan internet yang masif, internet menjadi energi terbesar dari kehidupan di era ini. Internet membuat semua informasi yang ada di dunia ini menjadi sangat mudah didapatkan, bahkan dalam hitungan detik.

Bila ingin bersaing di era digital ini organisasi perlu segera meningkatkan kemampuan dan keterampilan sumberdaya manusia aparatur melalu in house tranning atau on the job training pemannfaatan teknologi digital mencapai daya saing dan produktivitas tinggi. Dengan melakukan hal ini sumber dayaorganisasi akan bekinerja tinggi mampu berinovasi dalam Revolusi Industri 4.0, melalui pemanfaatan implementasi teknologi digital dan komputasi kedalam Industri.

Teknologi Informasi Komputer, (TIK) mendasari revolusi digital adalah perkembangan komputer elektronik digital, yaitu komputer / laptof, dan khususnya mikroprosesor dengan kinerjanya yang terus 
meningkat, yang memungkinkan provedor dan vendor teknologi komputer untuk tertanam ke berbagai objek besar dari kamera ke pemutar musik pribadi. Sama pentingnya adalah pengembangan teknologi transmisi termasuk jaringan computer (Networking), Internet dan penyiaran digital. Ponsel 3G dan 4G, yang tumbuh pesat penetrasi sosial pada tahun 2000, juga memainkan peran yang sangat besar dalam revolusi digital karena mereka secara bersamaan memberikan hiburan di mana-mana, komunikasi, dan konektivitas online.

Komputer yang kita gunakan sekarang ini tidak serta merta muncul begitu saja melainkan melalui proses yang panjang dalam evolusinya. Era komputer elektrik dimulai sejak ditemukannya komputer elektrik yang menerapkan sistem aljabar Boolean pada dekade 1940-an. barulah pada dekade 1980-an komputer menjadi mesin yang akrab bagi masyarakat umum di negara maju.

Internet pada awalnya bertujuan untuk keperluan militer Amerika untuk membuat sistem jaringan komputer yang tersebar dengan menghubungkan komputer di daerah-daerah vital untuk mengatasi masalah bila terjadi serangan nuklir dan untuk menghindari terjadinya informasi terpusat, yang apabila terjadi perang dapat mudah dihancurkan, namun pada era digital ini kebutuhan akan internet telah merambah keseluruh bagian kehidupan dan seolah-olah tak bisa dipisahkan dari kehidupan manusia.

Penggunaan smartphone sudah menjadi pemandangan umum masyarakat kita, tidak peduli dari kalangan mana, dengan latar belakang pekerjaan apa pun, bahkan dari golongan usia manapun. Pada awalnya handset pertama dilahirkannya pada tahun 1973 dengan bantuan tim Motorola dengan berat dua kilogram, pada tahun 1983 harga ponsel berkisar 36 sampai 90 Juta Rupiah.

Pada tahun-tahun terakhir ini teknologi smartphone semakin cangggih dengan berbagi fitur baru yang makin beragam ditanamkan didalamnya, kemampuan produksi massal pada teknologi superkonduktor dan mikroprosesor yang mampu menekan biaya produksi sehingga berimplikasi pada semakin murah dan terjangkaunya harga smarphone dipasaran, membawa dampak pada penggunaan luas hampir tanpa batas dari teknologi smarphone ini.

Situs jejaring sosial merupakan sebuah web berbasis pelayanan yang memungkinkan penggunanya untuk membuat profil, melihat list pengguna yang tersedia, serta mengundang atau menerima teman untuk bergabung dalam situs tersebut. Hubungan antara perangkat mobile dan halaman web internet melalui "jaringan sosial" telah menjadi standar dalam komunikasi digital. Awal mula situs jejaring sosial ini muncul pada tahun 1997 dengan beberapa situs yang lahir berbasiskan kepercayaan setelah itu kejayaan situs jejaring sosial mulai diminati mulai dari tahun.

Di era digital seperti sekarang ini, tentunya diperlukan sosok pemimpin yang terampil dalam pemanfaatan teknologi informasi, komunikasi dan semua peralatan komputer dan internet. Pemimpin adatif dan tidak yang "gaptek" dan "jadul" dalam mengoperasionalkan peralatan teknologi informasi akan ditinggalkan oleh masyarakat, khususnya generasi milenial, karena tidak sesuai di era kekinian dengan kebutuhan. Dibutuhkan pemimpin yang memiliki visi teknologi informasi, ramah terhadap media sosial, dan mampu berinteraksi di dunia maya menyapa warga dunia maya secara bebas dan terbuka.

Peningkatan kinerja organisasi sangat penting juga di dukung dengan sarana dan prasarana yang memadai.Sarana dan prasarana ini padahal sangat vital dalam kegiatan proses bekerja. Ketersediaan sarana dalam suatu organisasi mempunyai peran penting dalam terlaksananya proses bekerja.Sumber daya yang paling penting bagi suatu organisasi adalah orang yang memberikan kerja, bakat, kreativitas, dan semangat kepada organisasi".Oleh karena itu kesulitan sumberdaya manusia merupakan sumber masalah dalam organisasi. Konsekuensi dari hai ini adalah tersedianya sumber daya manusia yang mempunyai kapasitas sebagai perencana dan pelaksana program kegiatan. Kapasitas ini ditentukan oleh kapabilitas, kompetensi dan produktivitas kerja. Permasalahan pokok dalam penelitian ini adalah penyesuaian kepemimpinan di era digitalisasi. Kurangnya sarana dan prasarana dan keterbatasan sumberdaya Aparatur. 


\section{METODE}

\subsection{Populasi dan Sampel}

Populasi yang digunakan dalam penelitian ini adalah pegawai yang bekerja pada pemerintahan Provinsi Riau. Pemerintahan merupakan salah satu lembaga yang berperan dalam mendorong terwujudnya efektivitas, efisiensi dan akuntabilitas yang tinggi pada pengelolan keuangan dan kekayaan Provinsi Riau.

Pengambilan sampel ditentukan dengan metode purposive sampling menurut Sugiyono 2010 adalah teknik untuk menentukan sampel penelitian dengan beberapa pertimbangan tertentu yang bertujuan agar data yang diperoleh nantinya bisa lebih representatif.

\subsection{Jenis dan Sumber Data}

Data yang digunakan dalam penelitian ini terdiri dari data primer. Data primer merupakan sumber data penelitian yang diperoleh secara langsung dari sumber asli atau tanpa melalui media perantara $\mathrm{J}$. Supranto (1994) dalam Soraya (2010). Data primer yang digunakan dalam penelitian ini diperoleh dari hasil kuesioner yang disebarkan pada sampel yang telah ditentukan (Pegawai di pemerintahan Provinsi Riau).

\subsection{Metode Pengumpulan Data}

Metode Pengumpulan data primer dari responden dilakukan dengan survei, yaitu dengan cara mengumpulkan data pokok (data primer) dari suatu sampel dengan menggunakan instrumen kuisioner dengan cara memberikan daftar pertanyaan tertulis kepada responden. Kuisioner ini didistribusikan secara langsung kepada responden yaitu di Pemerintahan provinsi Riau. Kuisioner ini didistribusikan kepada 3 orang pegawai di Organisasi Perangkat Daerah yang sudah di pilih sebagai sampel. Setiap paket kuisioner terdiri dari dua bagian yang harus dijawab oleh responden dengan mengikuti perintah yang terdapat didalam setiap bagian. Bagian pertama berisi mengenai data demografi responden. Bagian kedua adalah pernyataan yang berhubungan dengan Kepemimpinan

\section{HASIL DAN PEMBAHASAN}

Proses untuk menjadi pemimpin yang autentik dimulai dengan pengetahuan. Sebagai pemimpin perlu berpikir dan memahami keterampilan, kompetensi, dan informasi teknis yang diperlukan agar bisa mengelola tim dalam dunia kerja yang modern.

Bagi banyak pemimpin, digital dapat menjadi 'frenemy' (teman/lawan). Hal ini bisa menjadi wadah untuk meningkatkan pengaruh, prestise, dan kekuatan pemimpin. Namun terdapat pula peluang tersembunyi, di mana 'digital' bisa menjadi media yang menjerumuskan pemimpin pada 'ego'. Seorang pemimpin mungkin semakin terkenal karena adanya social media, sehingga enggan untuk berinteraksi dengan orang-orang yang dianggap 'tidak selevel'.

Pengetahuan diperlukan oleh seorang pemimpin, tidak hanya itu di era digital ini sebagai pemimpin kamu harus bisa fleksibel agar dapat mengikuti perkembangan jaman yang dinamis.Persoalan Teknologi Informasi dan Komunikasi, di Pemerintah Provinsi Riau, akan di arahkan kepada keberlanjutan dan kemanfaatan digitalisasi. Akan tetapi beberapa tahun terahir ini sudah ada peningkatan yang cukup signifikan mengenai pengetahuan tentang digitalisasi.

Merangkul informasi yang tepat untuk menjadi pemimpin digital yang autentik cukup mudah. Tantangan sebenarnya dimulai ketika orang mulai mempraktekkan pengetahuan itu. Dalam dunia digital 
tidak ada lagi batasan dimana informasi dapat diakses dengan cepat dan mudah. Kemudahan ini mendorong orang untuk semakin meningkatkan inovasi.

Sebagai pemimpin tidak hanya memberikan delegasi dan perintah, tetapi perlu bagi seorang pemimpin untuk terlibat dalam proyek yang ada. Bekerja bersama tim dan berinteraksi dengan banyak anggota Organisasi menjadi salah satu cara untuk menjadi pemimpin yang tidak hanya terjebak pada 'status', tetapi juga melakukan 'aksi' sesuai dengan kapasitas yang dibutuhkan. BeberapaOrganisasi Perangkat Daerah yang menggunakan sistem digital untuk memantau serta mengambil keputusan.

Salah satunya adalah E-Office yang sudah mulai di terpkan di seluruh Organisasi Perangkat Daerah Provinsi Riau. Dari aplikasi tersebut pemimpin bisa memantau absensi,izin,sakit dinas luar dan lainnya. Sehingga semua kegiatan ter record pada server digital. Hal yang paling sulit untuk menjadi pemimpin sejati adalah tahap implementasi atau perakteknya setiap kita ditantang untuk bisa mewujudkan secara konsisten perannya sebagai pemimpin dalam organisasi. Tidak hanya itu, sebagai pemimpin kita harus bisa menuntun anggota organisasi atau staf untuk mencapai tujuan, bertindak sesuai pada nilai-nilai, dan yang terpenting menjaga integritas.

Semua orang bisamengatasi setiap hambatan atau rintangan dalam mencaai tujuan organisasi belajar dari berbagai pengalaman untuk mencapai keberhasilan. Pengalaman-pengalaman ini jelas membentuk jati diri seorang leadership yang adaptif saat ini, sekaligus mempengaruhi dalamsetiap pengambilan keputusan.Hal di maksud di maknai dengan VOCA vs VOCA,(Vision / Visi, Understanding / Pemahaman, Clarity / Kejelasan, Awareness/ Kesadaran, versi Volatility / Berubah-ubah, Uncertainty / Ketidak pastian, Complexity / Kompleksitas, Ambiguity / Kemenduaan)

Digital sendiri bisa berarti 'kita semakin tidak terkendali'. Tidak ada cara untuk mengelola setiap komponen tentang bagaimana orang lain bereaksi, merespond, atau mengkritik kehidupan. Maka, sangat penting sebagai pemimpin untuk bisa merangkul dan menerima sekaligus, baik pihak yang pro dan kontra.Pemimpin pada era digital ini akan lebih sering berkomunikasi dan terlibat dengan banyak audiens. Sebagai pemimpin, harus bisa membangun perspektif global dan meminimalisir perspektif yang subyektif dalam menciptakan pelayanan publik yang paripurna. Bahkan seorang leadershif harus bisa menambahkan perspektif visioner yang unik terhadapgagasan baru yang dapat di adaptasikan kedalam organisasi atau inovasi.

Sebagai pemimpin di era digital Organisasi Perangkat Daerah Provinsi Riau, sesuai Peraturan Pemerintah Nomor 18 Tahun 2016, konsisten untuk menerapkan ketiga hal tersebut diatas dengan lebih serius, sehingga bisa membawa Organisasi pada kesuksesan pencapain visi dan misi Kepala Daerah.

\section{KESIMPULAN}

Komunikasi dan pemimpin adalah dua hal yang tidak pernah bisa terlepaskan. Tiada pemimpin tanpa komunikasi dan sebaliknya komunikasi yang baik memerlukan sifat kepemimpinan. Era digital menyebabkan proses komunikasi yang terjadi didasarkan pada pengiriman simbol yang sifatnya sangat verbal dan abstrak. Pemaknaan didasarkan pada pemahaman atas posisi antara sumber dan penerima yang berada pada konteks yang berbeda. Sehingga pemahaman terhadap kemajuan teknologi harus dimiliki oleh setiap pemimpin. Seorang pemimpin harus sadar bahwa secara langsung atau tidak, disengaja atau tidak selalu dilihat orang, sehingga dirinya adalah teladan bagi orang lain. Salah satu wahana untuk mencapai kepemimpinan di era teknologi dirancang melalui pembentukan karakter ASN sebagai salah satu komponen perekat pemersatu bangsa perwujudan masyarakat . Pendidikan karakter ASN sifatnya pervasive artinya tidak seketika atau instant, tetapi perlu waktu yang cukup lama melalui coaching cleanic, learning, on the job trainning, community of practice, budaya kerja, dan tentunya pengembangan kompetensi di era new normal sangatlah penting, antara lain ; Digitalisasi, Integrasi (Penerapan ASN 
Corporate University), dan Kontektualisasi, (berpikir kritis, kratif dan inovatif dalam upaya meningkatkan kontribusinya bagi kinerja organisasi ).

Kepemimpinan di Provinsi Riau, telah beradaptasi terhadap pemanfaatan teknologi informasi 4.0, yang berkembang sangat cepat ke 5.0. Semua jenis pelayanan publik baik secara internal atauun eksternal di Organisasi Perangkat Daeraah telah menggunakan aplikasi berbasis website yang di maknai sebuah kumpulan halaman pada suatu domain di internet yang di buat dengan tujuan tertentu dan saling berhubungan serta dapat di akses secara luas melalui halaman depan, (homepage) menggunakan sebuah browser URL, (uniform resource locator), istilah lain untuk menyebut alamat website. Untuk menyikapi dinamika perkembangan tersebut diatas secara konsistendengan menerapkan ketiga item yakni knowing,doing dan being.

\section{DAFTAR PUSTAKA}

[1] Amalia, Soraya. 2010. Persepsi Pegawai Pajak Terhadap Pemanfaatan Teknologi Informasi Pada Kinerja Individual (Studi Kasus pada KPP Pratama Tegal). Universitas Diponegoro.

[2] Danim, Sudarwan. 2004. Motivasi Kepemimpinan \& Efektivitas Kelompok. Jakarta: PT Rineka Cipta

[3] Kartono,Kartini. 1994. Pemimpin dan Kepemimpinan. Jakarta:PT Raja Grafindo.

[4] Sondang P. Siagian. 2010. Manajemen Sumber Daya Manusia, Bumi Aksara, Jakarta.

[5] Sugiyono. 2010. Metode Penelitian Pendidikan Pendekatan Kuantitatif, kualitatif, dan R\&D. Bandung: Alfabeta

[6] Sri Sediyaningsih 2014.Kepemimpinan Di Era Digital Menuju Masyarakat Madani.

[7] Undang-Undang Nomor 25 Tahun 2009 ,dan Peraturan Pemerinah , Nomor 96 Tahun 2012, Tentang Pelayanan Publik.

[8] Wahjosumidjo (2005). Kepemimpinan Kepala Sekolah, Tinjauan Teori dan Permasalahannya. Jakarta: Raja Grafindo Persada.

[9] https://www.industry.co.id/read/51773/kepemimpinan-di-era-digital 